\title{
Study on Design of High-Rise Commercial Residential Complex
}

\author{
Yun Zuo \\ School of Architecture and Civil Engineering, Inner Mongolia University of Science \&Technology \\ 7 Arden Avenue, Baotou, China \\ 652779086@qq.com
}

Keywords: high-rise, commercial residential complex, form

\begin{abstract}
With the rapid development of social economy, high-rise residential and commer cial complex building is the main rend. There are numerous benefits of the high-rise comme rcial residential complex building. There are many types of high-rise residential and comme rcial complex building. They will help people to design the high-rise residential and commer cial complex building.
\end{abstract}

\section{Introduction}

High-rise commercial residential complex is a common form of the complex building. The form of the high-rise commercial residential complex building is formed a preliminary to the business services and residential function, based on some auxiliary building space. The high-rise commercial residential complex building has three dimensional spaces. The functional organization formed the high-rise commercial residential complex building to be high density, large capacity. It comes to be a multi-level interlaced structure, complex spatial structure. Living function is the basic function of the high-rise commercial residential complex building. Business function is the important constitute elements .The two main functions and auxiliary functions complement each other.

Modern commercial residential complex building was born in 50s to 60 s of this century. Just then the economy was in active development stage in Europe and America. With urbanization more and more people had migrated to the cities and the cities grew rapidly. After the industrial revolution, the construction of the city had got high speed development again. However, over following the principles of function subareas and the form and structure determinism which were the modernism theory, city construction was carried out in a simple expansion mode. The commercial function and the living function were relatively independent. The complex and interwoven diversification needs for city were ignored. The organic integrity of city was broken up. The traditional quality of city space was lost. City center was spotlighted and hollowed. There developed a practice that came to the growing vacancy rates, the social pathological complex phenomenon and as dry as a chip city space. Architects and city planners began to seek a way to deal with these phenomena and problems. They put forward that the city's characteristics must come from the rich and comprehensive and was called "organic compound". Many functions coordinated can meet the various needs of people and provide rich activities space to attract more levels of people. To mix many functions, we should first consider the two kind of main function model building. Commercial and residential bound up with citizen life. Under such age's background, the commercial residential complex building appeared in the basis of the multifunctional building within the theory of design. With the city revitalization movement, commercial residential complex building was came in the center of the city and play an important role in the revival of the city center area. After the emergence of modern complex building, there are growing signs of combining with the high-rise building. On the one hand, land resources are scarce which is bound to the building developing towards altitude. On the other hand, the pursuit of maximum interests of the city developers, the complex building has getting higher and higher [1].

China is a country with a large population. Residential and commercial activities necessary for survival occupies a major position in other activities, so a fusion of residential and commercial function in a building has a leap frog development across the top of the original single mode. In the mid '80s, the high-rise commercial residential complex building had been started with introduction 
and practice in China. With the rapid development of social economy and city construction, high-rise residential and commercial complex buildings have attracted more and more attention. Experience has proved that the high-rise residential and commercial complex buildings play a good role in the process of city construction and development in china. For example, to make rational use of the land, to improve the city environment, to solve the disjoint phenomenon between planning and monomer design, and to provide favorable conditions for the reconstruction of the old city, managing investment, energy saving, and so on.

\section{The Type of High-Rise Residential and Commercial Complex Building}

In our country, "tower building combined with skirt building" is the most common type of architecture in the high-rise residential and commercial complex building. "Tower building combined with skirt building" refers to one or more high-rise towers built in several stories podium. Living function zone is set in the part of towers. Commercial and other functions zones are set in podium. High-rise residential function combined with other functions is the essence.

\section{Single Type of High-Rise Residential and Commercial Complex Building}

\section{Point High-Rise Residential and Commercial Complex Building}

When the standard level was laid out just like a square, as long as it was wide, or puts forward the length -width ratio of approximately $1: 1$, the height of the building was greater than the plane of the length or width, so the high-rise complex building is called "point type high-rise complex building,"see Fig.1.From traffic system the core of organizations are designed, to make as much as the exterior walls have characteristic of residential function, to take in more houses, stairs, elevators and the level of transportation are concentrated together to form the core tube in the combination in the part of residential building and to ensure the necessary structural stiffness of high-rise residential. There can be much different effect of natural ventilation and lighting and variations of form in each dwelling unit. The point type high-rise complex building also has characteristic of many aspects. Due to the structure characteristics and the narrow space, large commercial space can not be set in the bottom layer of level standard in the point type high-rise complex building. To get more space for the occupants, it makes connections between commercial space and skirt building.

\section{The Board High-Rise Residential and Commercial Complex Building}

When the longitudinal length is much greater than the horizontal axis to the depth scale, the high-rise complex building is called "board high-rise residential and commercial complex building," see Fig.2. More human living in the board building should be a way of housing life than living in the tower building. No matter how to develop the society and human, close to nature the human natural ability is never erased. They shall evermore remain their personalities which are the love of sunshine and fresh air. There is an incurable tendency in creating a dark room inevitably, indoor ventilation in a point type of tower building. Those are fundamental flaws which can be improved in some extent [2].

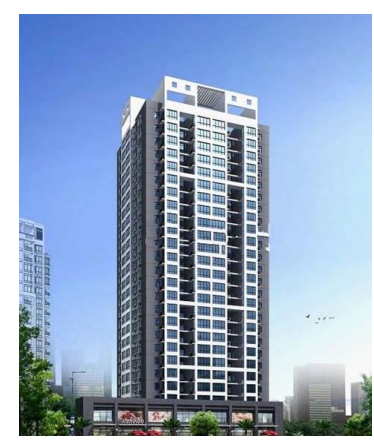

Fig.1 Antie high-rise residential and commercial complex building

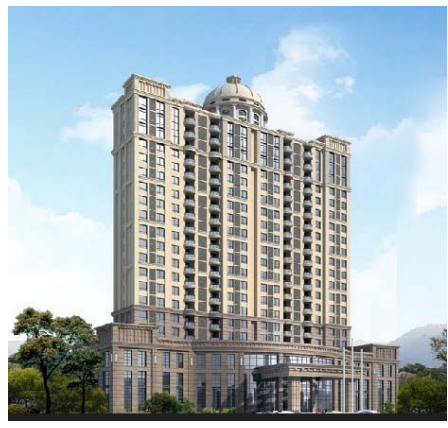

Fig.2 Huihe buiding

Altogether, the aboard high-rise building is much better in respect of quality than the tower high-rise building. South flow of convection air is better. Every house has a sunny room. People live 
in it with higher comfortable degree. The aboard high-rise building also has its limitation. Main is shown in those aspects which are in order to meet the conditions of sunshine, the community consisted of aboard high-rise buildings owns lower volume rates than the community consisted of point type of high-rise buildings. The external walls of the building have greater area. Insulating materials are more consumable. Two or three houses have one part of fire control stair which is a form of the aboard high-rise building. Efficiency of the elevator use is low. It is relatively high costs. The lower part of commercial space in the aboard high-rise building is used to set the shops that lined the street. The main characteristic of the aboard high-rise building has high usable frequency and regular space [3]. It has a good business reputation. Short of space and small uniform space would not have been appropriate for large commercial space.

\section{Group Type of High-Rise Residential and Commercial Complex Building}

Group type of high-rise residential and commercial complex building is a compound centre made up of one or more high-rise residential and commercial functions building. It is an architectural complex in the overall design, function and architectural art. Many buildings were coordinated and complementary form an indivisible whole. As the name implies, group type of high-rise residential and commercial complex building is based upon complex and combination. At the same time to meet the full requirements of the multi functions, there are always things in the complex building to think about, such as combination of the flat form, external and internal space sequence, so as to form a unified organic and changed coherent group image. It satisfies the user's requirements both functionally and emotionally in the design of the group type of high-rise residential and commercial complex building. The complexity of the building itself will inevitably lead to be the rich and diversified characters. Design methods of a series of variable sections coordination with each other in the group type of high-rise residential and commercial complex building are often taken these approaches.

\section{Combination of the Same Shape of Single Buildings}

The design method simple and easy to understand the geometry adopted in the Combination of the same shape of single buildings which is inevitably integrated. When the same shapes are combined, the outside of the building is organic united naturally, see Fig.3.

\section{Combination of the Similar Shape of Single Buildings}

In the high-rise complex building, if the plan of one building is similar to other buildings and all of the windows have a uniform size, there are the coordination relationships among the buildings, see Fig.4.

\section{Combination of Subordinate}

Part of the buildings achieved complete dominance in the combination of subordinate. The high-rise complex building embodies the unity of functions and forms. It is reflected in two aspects, one is width and short subordinated to height, another is incomplete shape subordinated to complete shape; this combination is more prominent the harmonious image of whole, see Fig.5.

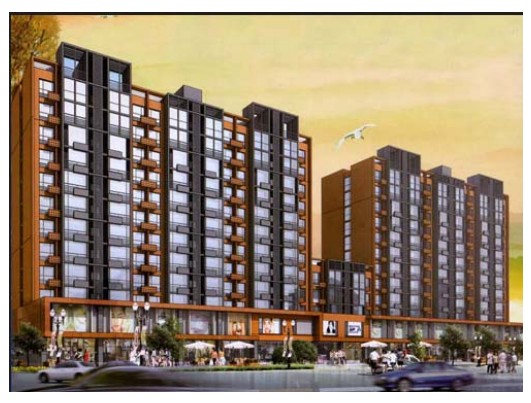

Fig.3 Tangshan Haigang

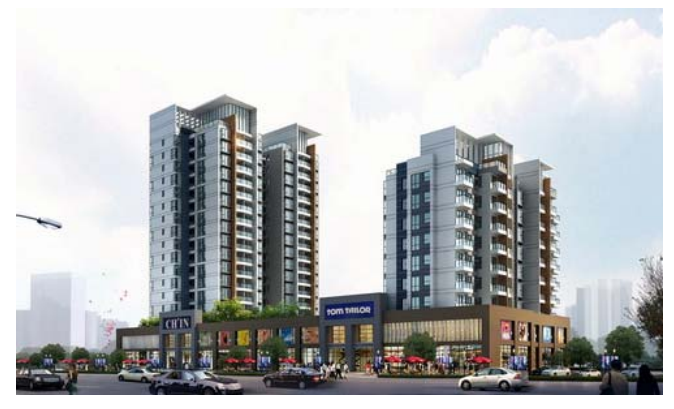

Fig.4 high-rise residential and commercial complex building. 


\section{Combination of Different Single Plans and Disordered Arrangement}

There's a lack of fussiness about the bodies order and coordination in the combination. According to the city and the terrain environment, the variety volume, different visual effects from every angle should be shown. The combination of rich spaces will create in isolation single building from modular, see Fig.6.

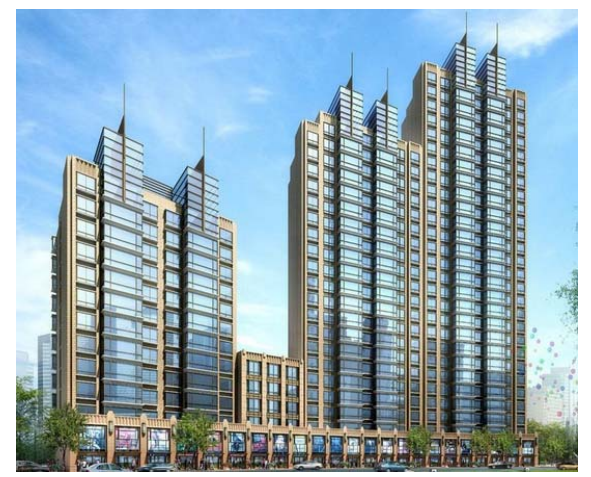

Fig.5 Qiandi building

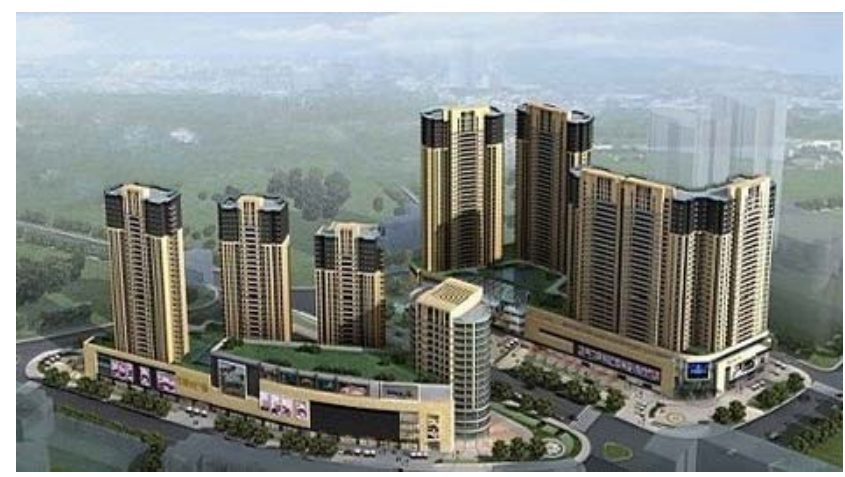

Fig.6 Qingdao Taishan road building

\section{Architectural space of residential and commercial complex building combined with city space}

People put a high premium on the space structure to realize the space. The space structure of high-rise residential and commercial complex building is peoples potted demand for space. Except for the character of space, such as level, area, publicity and the demand of settled space, it is an option to the patterns of the space structure that concerns the life and energy of the building. In particular, as the high-rise residential and commercial complex building developed, covering more and more functions, it tends to coalesce into huge and massive city within city [4]. The inside of the building is not only a collection of rooms and corridors, but to be a unit include a bustling "street", the public "square" to contact the various requirements of the functional. Public spaces such as road and transportation center have been used as structure inside the building to recognize the complicated function and the concrete image. Public spaces such as the vertical transportation space linked to internal functional unit. Yard and atrium the factors of space form are comprehensive expression of factors of space form[5]. They apply to the architectural multipurpose spaces. They are urban space form created sense of place. They are a necessary consequence of the concentration of urban spaces and urbanization of architectural spaces. The architectural spaces bind with urban spaces through the yard and atrium in the high-rise residential and commercial complex building.

\section{Summary}

Under the background of high-rise building increasingly integrated, high-rise residential and commercial complex building is bound to a trend of high-rise residential and commercial building in the future. A variety of the architectural forms of high-rise residential and commercial building have been analyzed. The results described above are also expected to help the design of high-rise residential and commercial complex building.

\section{References}

[1] Wang Yulong: Design and Research of High Commercial Residential Complex Buildings. Master Thesis. Harbin Institute of Technology, 2007, p.23-25. In Chinese.

[2] Wu Yunxiao: About the Design of Modern High-Rise Commercial Residential Buildings [J]. China Homes, 2014 (3) , p.50.In Chinese. 
[3] Lu Minjun, Design of High-Rise Commercial Residential Buildings[J].Construction \& Design for Engineering ,2002(3), p.20.In Chinese.

[4] Zhang Nanhui: Design and Research of Urban Comprehensive Architecture of Commerce and Housing. Master Thesis. Wuhan University, 2005, p.27. In Chinese.

[5] He Zhanming: Design and Research of High-Rise Commercial Residential Building[J]s. Journal of Huaqiao University, 1995(10), p.395.In Chinese. 